\title{
Lumbar Disc Herniation Might Spontaneously Regress, While Neuropathic Pain Might Start: Retrospective Clinical Study
}

\author{
Yener Akyuva $^{1, \mathrm{a}}$, Necati Kaplan ${ }^{2, \mathrm{~b}}$, Boran Urfalı ${ }^{1, \mathrm{c}}$, Özkan Özger ${ }^{3, \mathrm{~d}^{*}}$, Erdinç Civelek ${ }^{4, \mathrm{e}}$, \\ Serdar Kabataș,f, Yurdal Serarslan ${ }^{1, \mathrm{~g}}$
}

${ }^{I}$ Department of Neurosurgery, Tayfur Ata Sökmen Faculty of Medicine, Hatay Mustafa Kemal University, 31060 Hatay, Turkey

${ }^{2}$ Neurosurgery Clinic, Corlu Reyap Hospital, Rumeli University, 34570 Ístanbul, Turkey

${ }^{3}$ Neurosurgery Clinic, Medicalpark Canakkale Hospital, Rumeli University, 34570 İstanbul, Turkey

${ }^{4}$ Department of Neurosurgery, Gaziosmanpaşa Training and Research Hospital, University of Health Sciences, 34668 Istanbul, Turkey *Corresponding author

\begin{tabular}{l|l} 
A R T I C L E I N F O & A B S T R A C T \\
\hline $\begin{array}{l}\text { Research Article } \\
\text { Received : 30/08/2020 }\end{array}$ & $\begin{array}{l}\text { Lumbar disc herniation (LDH) is a common cause of low back pain and radicular pain. The aim of } \\
\text { our study was to evaluate the regression of LDH in patients who are considered to require surgical } \\
\text { treatment but prefer conservative treatment. Patients who presented between January 2018 and June } \\
2020 \text { and who did not accept the recommended surgical treatment following a diagnosis of LDH } \\
\text { based on clinical and radiological findings were retrospectively reviewed. All 12 of the patients } \\
\text { included in the study showed spontaneous regression of LDH during outpatient clinical follow-up. } \\
\text { Our study included 12 patients (seven male and five female). The mean age was 46.5 (the youngest } \\
\text { was 30 years old; the oldest was 70 years old). Regression was observed at the L2-L3 level in two } \\
\text { patients (10\%), at the L4-L5 level in four patients (40\%), and at the L5-S1 level in six patients } \\
\text { (50\%). On the follow-up examination of all patients, the severity of their pain was evaluated with } \\
\text { the Visual Analogue Scale, and all patients described a reduction in pain (min: 2, max: 8). Ten } \\
\text { patients described radicular pain at the initial examination, eight patients received physical therapy } \\
\text { and rehabilitation treatment before the follow-up examination, and nine patients described } \\
\text { neuropathic pain at the follow-up examination. Spontaneous regression of LDH is rare. While } \\
\text { conservative treatments provided partial improvement in the complaints of these patients, } \\
\text { conservative treatments usually cannot prevent the development of neuropathic pain. }\end{array}$ \\
$\begin{array}{l}\text { Keywords: } \\
\text { Conservative treatment } \\
\text { Herniation } \\
\text { Intervertebral disc } \\
\text { Regression }\end{array}$ &
\end{tabular}

a@yenerakyuva@hotmail.com

b@drnecatikaplan@hotmail.com d@ozkanozger@hotmail.com f@kabatasserdar@hotmail.com
iD https://orcid.org/0000-0001-5672-0566 (iD) https://orcid.org/0000-0001-7257-8379 (i) https://orcid.org/0000-0002-3988-4064

\section{Introduction}

About $80 \%$ of the population suffers from low back pain at least once in their lives. One of the most important pathologies that cause low back pain is lumbar disc herniation (LDH). It is also a serious public health problem, as it results in labor loss and requires medical treatment (Ocak, 2007). LDH develops as a result of the herniation of the nucleus pulposus (NP), which should be located in the intervertebral area, to the central canal after damage to the annulus fibrosus (AF). This may cause symptoms such as pain, neuromotor deficit, and urinary incontinence (Martin, 2002).

Conservative treatment is the first-line treatment for LDH. The aim is to relieve pain and inflammation in patients, to increase function, to encourage early activity, to prevent recurrence of complaints, and to ensure a return to normal life as early as possible. However, sometimes surgical treatment of LDH is inevitable. Unresponsiveness to conservative treatment, chronic pain, progressive neuromotor deficit, and even severe neurological syndromes such as cauda equina and drop foot are the findings that require surgical treatment (Awad, 2006).

The most effective radiological method for diagnosing $\mathrm{LDH}$ is magnetic resonance imaging (MRI). MRI presents to clinicians in detail at what level and in what condition (bulging, protruded, extruded, or sequestered) the herniated component is. It also helps in detecting concomitant pathologies such as annulus rupture, spondylolisthesis, and modic degeneration. The radiological test results along with the clinician's examination allows the clinician to recommend a treatment to the patient (Herzog, 1996). 
The blood supply to the NP, which depends on diffusion in the intervertebral area, is disrupted after herniation. On the one hand, this compresses neural structures and causes severe syndromes, and on the other hand, it becomes difficult to maintain tissue viability. Regression of LDH is observed in $1-2 \%$ of patients (Keskin, 2010; Aktoklu, 2020). However, waiting for the regression of LDH is not recommended when severe radiological and clinical findings are present (Hansson, 2007). In this research, our study includes the findings of patients who were considered to require surgical treatment after radiological and clinical examination but did not agree to surgical treatment and who showed regression of lumbar disc herniation in their follow-ups.

\section{Materials and Methods}

Patients who were admitted to the neurosurgery clinic between January 2018 and June 2020 and who did not accept surgical treatment despite it being recommended following an LDH diagnosis based on radiological and clinical findings were retrospectively reviewed. This is a multi-centre study, and the data of 1,096 patients were analysed. Data from the initial and follow-up examinations of patients who presented to the same physician with ongoing complaints were analysed. During the examinations of the patients, patients reported the severity of their pain with the help of the Visual Analog Scale (VAS) (Lim, 2018). The patients were provided with descriptions of radicular pain and neuropathic pain and identified which one was most similar to their pain. The type and duration of pain, examination findings, conservative treatments received, and radiological and demographic information were recorded in the hospital data system. Spontaneous regression of LDH was detected in the outpatient clinical follow-ups of the 12 patients whose data we analyzed in the study. This study was planned in accordance with the Declaration of Helsinki.

\section{Statistical Analysis}

The Statistical Package for the Social Sciences version 21.0 software (IBM Corp., Armonk, NY, USA) was used for statistical analysis. Continuous data were summarized as mean \pm standard deviation, while categorical data were summarized as number and percentage. For comparisons between groups, the two-sample t-test and correlation test were used to evaluate the correlation between independent categorical variables. The level of statistical significance was set at $\mathrm{P}<0.05$.

\section{Results}

Our study included 12 patients - seven male (58.3\%) and five female $(41.6 \%)$ patients. The mean age was 46.5 years(the youngest patient was 30 , and the oldest patient was 70). When the ages of the patients in the study were analysed by gender, the mean age in males was $49.4 \pm 16.4$ years, and the mean age in females was $43 \pm 9.3$ years. The age of patients ranged between 30 and 70 years in males and between 34 and 56 years in females.

Regression was observed at the L2-L3 level in two patients (10\%), at the L4-L5 level in four patients (40\%), and at the L5-S1 level in six patients $(50 \%)$. The predominant component of the herniated disc was found to be located to the left of the central canal in $50 \%$ of the patients, to the right in $40 \%$ of the patients, and centrally located in $10 \%$ of the patients (Figure 1-12).

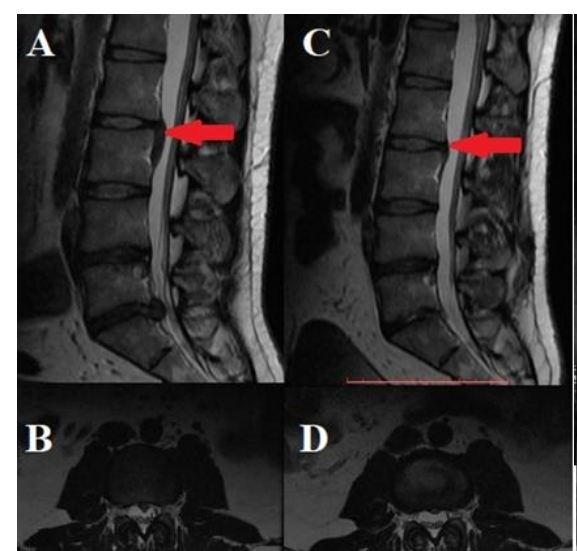

Figure 1.

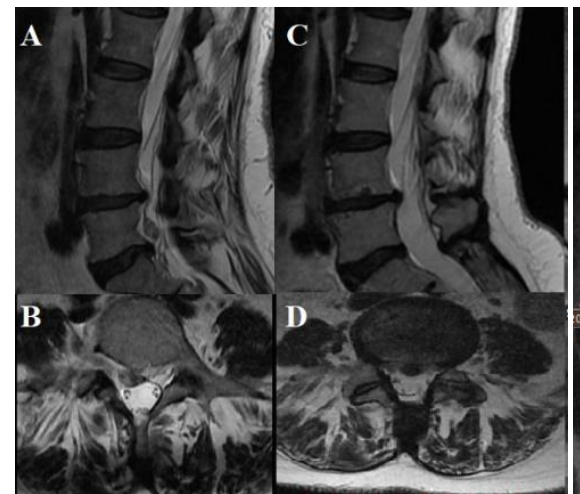

Figure 4.

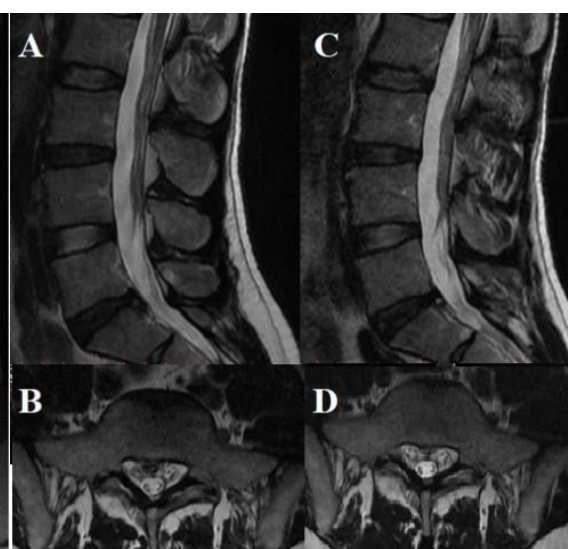

Figure 2.

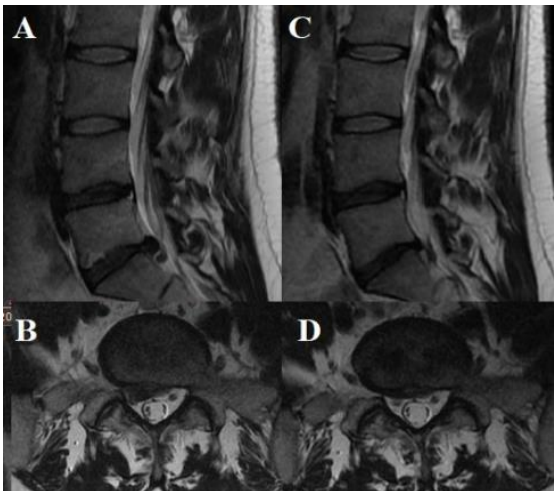

Figure 5.

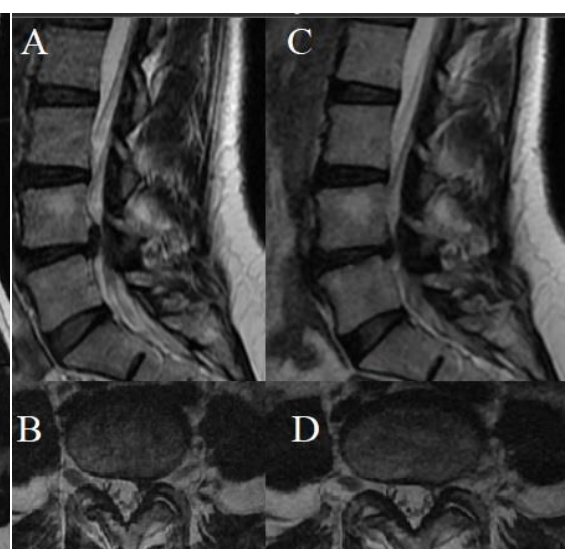

Figure 3.

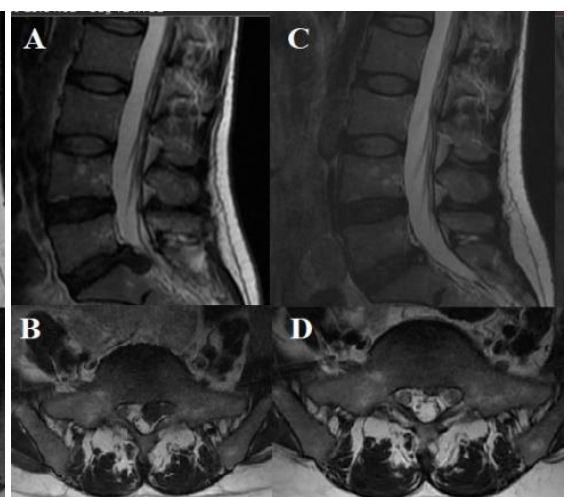

Figure 6. 


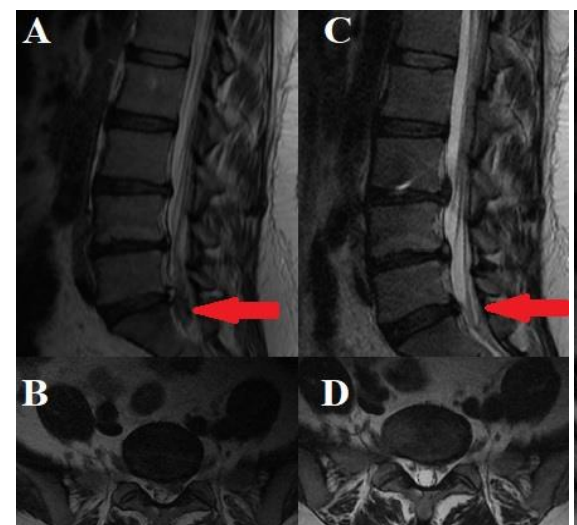

Figure 7.

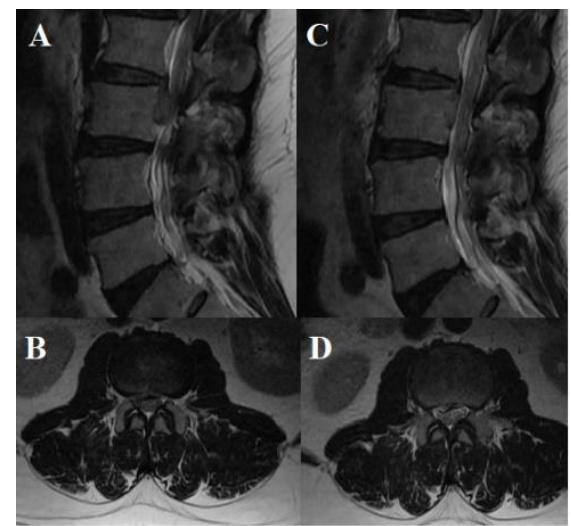

Figure 10

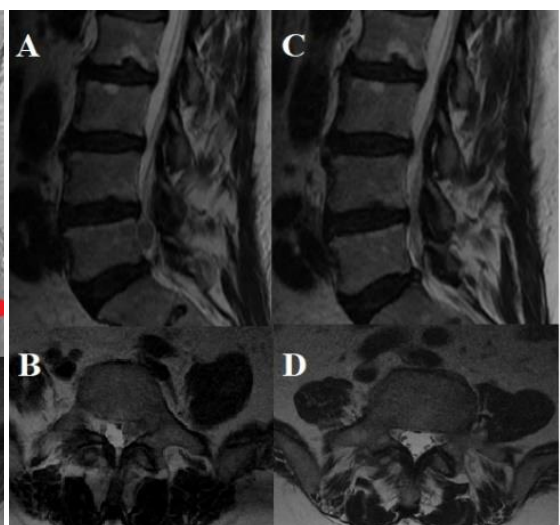

Figure 8.

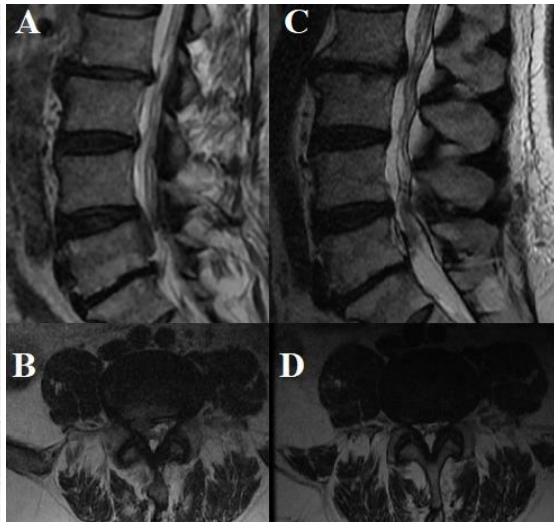

Figure 11

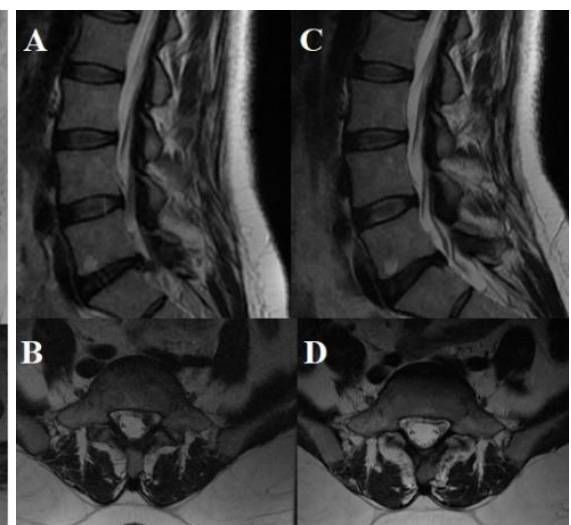

Figure 9.

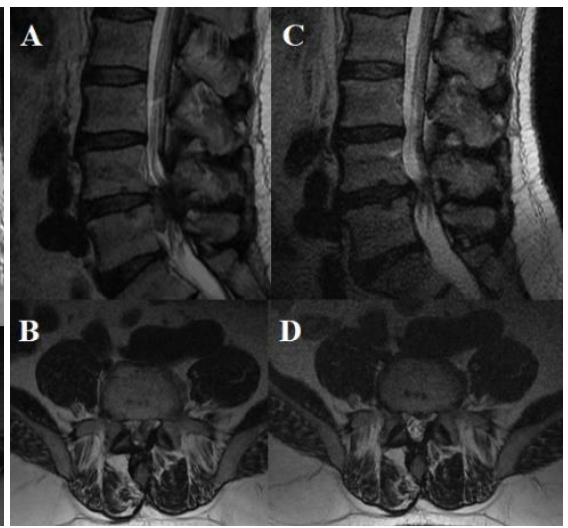

Figure 12.

Figure 1-12. Sagittal and axial lumbar MRI scans of all patients show sequestrated or extruded disc hernias before and after regression.

Table 1. Demographical, radiological and clinical features of patients with regression of lumbar disc herniation

\begin{tabular}{l|llllllllll}
\hline PN & G & A & Level & Side & Herniation type & RP & T & NP & PTR & VAS \\
\hline 1. & M & 32 & L2-L3 & Central & Disc Extrusion & + & 12 & - & - & $8->1(+7)$ \\
2. & M & 37 & L5-S1 & Central & Disc Extrusion & + & 4 & + & + & $7->3(+4)$ \\
3. & F & 44 & L4-L5 & Left & Disc Extrusion & + & 14 & + & + & $9->4(+5)$ \\
4. & F & 56 & L4-L5 & Right & Sequestereddisc & + & 7 & + & + & $9->2(+7)$ \\
5. & M & 30 & L5-S1 & Right & Disc Extrusion & + & 8 & - & - & $8->2(+6)$ \\
6. & F & 34 & L5-S1 & Left & Disc Extrusion & + & 8 & + & - & $9->5(+4)$ \\
7. & F & 34 & L5-S1 & Left & Sequestereddisc & - & 3 & + & - & $8->3(+5)$ \\
8. & M & 70 & L5-S1 & Left & Sequestereddisc & + & 6 & + & + & $9->1(+8)$ \\
9. & F & 47 & L5-S1 & Left & Disc Extrusion & + & 5 & + & + & $9->7(+2)$ \\
10. & M & 52 & L2-L3 & Right & Disc Extrusion & - & 3 & - & + & $9->1(+8)$ \\
11. & M & 66 & L4-L5 & Right & Disc Extrusion & + & 10 & + & + & $9->5(+4)$ \\
12. & M & 59 & L4-L5 & Left & Disc Extrusion & + & 4 & + & + & $9->6(+3)$ \\
\hline
\end{tabular}

PN: Patient numbers, G: Gender, M: Male, F: Female, A: Age (Year), RP: Radicular pain, T: Time (Mounth), NP: Neuropathic pain (Control examination), PTR: Physical Rehabilitation Therapy Treatment, VAS: Visual Analog Scale Change

On the follow-up examination of all patients, the severity of their pain was evaluated with the VAS score, and all patients described a reduction in pain (min: 2, max: 8). Ten $(83.3 \%)$ patients described radicular pain on the initial examination, eight patients $(66.6 \%)$ received physical therapy and rehabilitation (PTR) treatment before the follow-up examination, and nine patients $(75 \%)$ described neuropathic pain on the follow-up examination. Demographic, radiological, and clinical information about the patients with regression of lumbar disc herniation is provided in Table 1.

The statistical correlation between radicular pain and VAS score changes of the male and female patients was analysed by the two-sample t-test. The resulting $\mathrm{P}=0.348$ value showed that there was no statistically significant difference between the male and female genders in terms of radicular pain and VAS score changes. In other words, radicular pain and VAS scores did not change by gender.

\section{Discussion}

In many patients with $\mathrm{LDH}$, back and leg pain is substantially relieved by conservative treatments. If there is no change in a patient's pain complaints despite 2-4 weeks of medical treatment or if the patient describes a progressive neuromotor deficit, it is essential to use advanced imaging techniques (Ocak, 2007; Awad, 2006). We evaluated patients who were considered to require 
further treatment based on neurological examination findings with lumbar MRI. In our study, there are, coincidentally, no patients with progressive neurological deficit and/or cauda equina syndrome.

After lumbar MRI, surgical treatment was recommended to patients who had significant compression on neural structures on radiological examination, who were unresponsive to conservative treatment, and who had a partial neurological deficit. The population of our study consisted of patients who refused surgery due to the recommendation for spinal fusion, their young age, or the presence of additional health problems, etc. Over time, these patients returned to the same physician for follow-up after receiving some sort of conservative treatment, and regression of $\mathrm{LDH}$ was detected.

It has been demonstrated in the literature that $\mathrm{LDH}$ that is not surgically treated and causes symptoms can spontaneously regress. However, the mechanism of regression has still not been fully explained. There are some hypotheses regarding this. The first is that regression occurs due to dehydration. When herniated, NP loses water at the cellular level and shrinks over time. The second theory is the mechanism of resorption, which is widely accepted as the primary physiopathological process behind regression. Herniated NP tissue is perceived by the autoimmune system as a foreign body. The inflammatory process is initiated, especially by phagocytic cells through neovascularization. A herniated NP is cleaned with enzymatic degradation and phagocytosis. Although other theories have also been suggested, they have not been as widely accepted as these two theories (Aktoklu, 2020; Yaycioglu, 2011, Doita, 1996).

When we reviewed the literature, we observed that most of the studies on non-operative treatments for lumbar disc herniation mention methods such as massage, epidural injections, nerve root blocks, traction, acupuncture, and the use of a corset (Ocak, 2007; Awad, 2006; Tang, 2018). Our patients received such treatments until they returned for a follow-up examination after diagnosis. The literature states that methods such as physiotherapy, massage, and acupuncture can increase blood flow in the lumbar region and provide sufficient phagocytic cell migration in that region; these observations favour the resorption theory (Yaycioglu, 2011; Tang, 2018; Kaya, 2013). In our study, all the patients used locally effective medication (creams and lotions) as a conservative treatment, and eight patients also received physiotherapy for at least two weeks.

In a study carried out by Yaycioglu (2011) was reported two cases of spontaneous regression of LDH. They reported that LDH radiologically regressed in these patients, but pain complaints continued at different levels of severity and in different forms. Neuropathic pain may develop in neural structures that are damaged by long-term exposure to compression (Freynhagen, 2006). In our study, the patients were provided with descriptions of radicular pain and neuropathic pain during the outpatient clinical examination. Ten patients described radicular pain on the initial examination, and when asked to describe it with a VAS score on the follow-up examination, all of these patients reported decreased radicular pain. When questioned in detail during the follow-up examination, it was found that the persisting pain of nine patients was neuropathic pain. These patients were initiated on gabapentin treatment and benefited from it.

Neuropathic pain occurs due to uncontrolled electrical discharge from the nerve cell after damage. Structural changes in the nerve cell sheath over time make the pain chronic. Freynhagen et al.(2006) stated that neural structure damage develops in patients with chronic low back pain and, accordingly, patients complain about neuropathic pain. In our study, patients described longlasting radicular pain and stated that this pain changed over time. The pain at the initial assessment that patients described as withdrawal and contraction from the hip to the legs was replaced by patients' complaints about numbness, a sensation of electrical shock, and tingling.

Irwin et al.(2005) stated that examination and radiological tests should be evaluated together in a patient with multilevel lumbar disc herniation, and intervention in LDH is not necessary unless surgical indication develops. In our study, posterior stabilization was recommended, as one patient had LDH at two different levels, and one had a history of recurrent LDH. The patient with LDH at two levels did not agree to undergo posterior stabilization surgery, microdiscectomy was performed for the herniation causing clinical symptoms. In these patients, posterior stabilization was not performed after LDH was found to regress.

In our study, the regression of LDH was most commonly seen at lumbar spaces L5-S1 (50\%) and L4-L5 (40\%). Kayaci et al.(2014) reported that the most frequently detected LDH occurred at these levels in the patients they treated. They stated that the L5-S1 and L4-L5 levels were the areas where LDH developed most frequently since they are the most active segments. In line with the literature, we found in our study that $90 \%$ of our LDH cases (L4-L5, L5-S1) developed at the levels where LDH most frequently occurs. To the best of our knowledge, there are no studies in the literature on the regression of $\mathrm{LDH}$ in these segments.

\section{Limitation of Research}

Since spontaneous regression of lumbar disc herniation is rarely seen, the population of our study is not homogeneous. Some patients received only myorelaxant and analgesic therapy, while some patients received physical therapy and rehabilitation. However, any patients received epidural injection or other minimally invasive surgical treatment.

\section{Conclusion}

A definitive treatment algorithm has still not been established for LDH, which is a very commonly diagnosed and treated disease, especially in neurosurgery clinics. As with our patients, neuropathic pain may develop as a sequel in cases that radiologically show spontaneous shrinkage. Our study confirms that surgical treatment should be considered first for lumbar disc herniation with surgical indication. In cases where surgical treatment is not preferred, radiological recovery may not be accompanied by clinical recovery. 


\section{References}

Aktoklu M, Ünal TC, Bozan T. 2020. Spontan Regresyon Gösteren Servikal ve Lomber Disk Hernisi: 3 Olgu Sunumu (Cervical and Lumbar Disc Hernia with Spontaneous Regression: 3 Case Report). Bozok Med J, 10(2): 234-237.

Awad JN, Moskovich R. 2006. Lumbar disc herniations: surgical versus nonsurgical treatment. Clin Orthop Relat Res, 443: 183-197. DOI: 10.1097/01.blo.0000198724.54891.3a

Doita M, Kanatani T, Harada T, Mizuno K. 1996. Immunohistologic study of the ruptured intervertebral disc of the lumbar spine. Spine (Phila Pa 1976), 21(2): 235-241. DOI: 10.1097/00007632-199601150-00015

Freynhagen R, Baron R, Tölle T, Stemmler E, Gockel U, Stevens M. 2006. Screening of neuropathic pain components in patients with chronic back pain associated with nerve root compression: a prospective observational pilot study (MIPORT). Curr Med Res Opin, 22(3): 529-537. DOI: $10.1185 / 030079906$ X89874

Hansson E, Hansson T. 2007. The cost-utility of lumbar disc herniation surgery. Eur Spine J, 16(3): 329-337. DOI: 10.1007/s00586-006-0131-y

Herzog RJ. 1996. The radiologic assessment for a lumbar disc herniation. Spine (Phila Pa 1976), 21(24 Suppl): 19-38. DOI: 10.1097/00007632-199612151-00004

Irwin ZN, Hilibrand A, Gustavel M, McLain R, Shaffer W, Myers M. 2005. Variation in surgical decision making for degenerative spinal disorders. Part II: cervical spine. Spine (Phila Pa 1976), 30(19): 2214-2219. DOI: 10.1097/01.brs.0000181056.76595.f7
Kaya E, Ozyurek S, Kaplan C, Gokcen B, Kose O. 2013. Regression of an extruded lumbar disc herniation after thermomechanical massage bed therapy. O A Orthopaedics, 1(2): 15

Kayacı S, Köksal V, Çağlar Ş. 2014. Lumbosakral Sinir Kökü Anomalilerinin Herniye Disk Fragmanı ile İlişkisi. Türk Nöroşirürji Dergisi, 24(1): 15-19.

Keskin, F. 2010. Spontaneous regression of extrude lumbar disc hernia. Selcuk Med J, 27(2): 116-117.

Lim KH, Salahudin MS, Hariri F. 2018. Evaluating full cup study, numeric pain rating scale, and visual analogue scale in assessing pain after surgical removal of lower third molar. Ann Dent UM, 24(2): 16-23.

Martin MD, Boxell CM, Malone DG. 2002. Pathophysiology of lumbar disc degeneration: a review of the literature. Neurosurg Focus, 13(2): E1. DOI: https://doi.org/10.3171/foc.2002.13.2.2

Ocak FDM, Karaaslan M, Tutar İ, Konuralp N, Güzelant AY, Özgüzel H. 2007. Lomber disk hernilerinde konservatif tedavi etkinliğinin klinik parametreler ve manyetik rezonans görüntüleme yöntemiyle değerlendirilmesi. Türk Fiz Tıp Rehab Derg, 53: 108-112.

Tang S, Mo Z, Zhang R. 2018. Acupuncture for lumbar disc herniation: a systematic review and meta-analysis. Acupunct Med, 36(2): 62-70. DOI: 10.1136/acupmed-2016-011332

Yaycıŏlu S, Ak H. 2011. Radyolojik Olarak Küçülme Gösteren Bel Fitıklarının Prognozu: Iki Olgu Sunumu. Anatol J Clin Investig, 5(3): 156-159. 